\title{
Norman Feather, 1904-1978
}

Professor Norman Feather, FRS, died on 14 August 1978 at the age of 73. His death has removed one of the last of that brilliant group of young men who gathered round Rutherford at the Cavendish Laboratory, and later guided the postwar expansion and flowering of academic physics in Britain.

Feather was born at Crimsworth, in the West Riding, the son of two school teachers. At Bridlington School he came under the influence of an inspiring science master, and this led him to decide to study physics at Trinity College, Cambridge. In 1926 ษ Feather was awarded his BA degree at is Cambridge, and the BSc degree of the University of London.

For the next three years he worked as a research student, under Chadwick, on the development of cloud-chamber techniques and their application to a study of the rare long-range $\alpha$-particles from Radium-C. In 1929 he was awarded a Fellowship of Trinity College. The award was for a period of four years, and he spent the first of these years at Johns Hopkins University in Baltimore, at the behest of R. W. Wood. He returned to Trinity College in 1930 and submittedsuccessfully-his PhD thesis.

In his luggage Feather had brought back with him 300 'dead' radon bulbs, from the Kelly Hospital in Baltimore, containing in all about 100 millicuries of polonium. It was with this polonium that Chadwick, Dee, and Feather established in 1932 the production of neutrons when beryllium was bombarded by $\alpha$-particles, and in particular Feather, using his automatic cloudchamber, produced the first clear evidence for the transmutation of nuclei by neutrons.

Feather's next cloud-chamber experiment was a study, jointly with Bretscher, of the photo-disintegration of the deuteron. The value they obtained for the deuteron binding energy was challenged by Bethe, on the basis of his theoretical studies of the rate of energy loss of charged particles in matter. The Bretscher-Feather value was subsequently vindicated by more refined experiments elsewhere. Feather had never doubted that it would be: his calibration data had been accumulated during years of painstaking observation and comparison.

Feather frequently pointed out to his colleagues and juniors that he had

\section{Sorry, for copyright reasons some images on this page may not be available online}

never been exposed to the higher reaches of mathematics nor to any quantum theory-'just a little applied mathematics'. And he would go on to maintain, with a glint in his eye, that there were still things to do in nuclear physics where insight and intuition were the best guides. When it was necessary his mathematics tended to rise to the occasion, as in his early studies of the statistics of the promptand delayed-coincidence techniques which he used in $\beta$-ray spectrometry and the investigation of nuclear isomerism, in the late 1930s. But when his insight and intuition were involved they were backed up by a vast and detailed knowledge of nuclear systematics, which found expression in his monograph on Nuclear Stability Rules (1952) and in his later writings on nuclear fission.

When Chadwick went to the Chair of Physics in Liverpool in 1935 Feather went with him, but remained there for only one year, during which he wrote his first undergraduate textbook, $A n$ Introduction to Nuclear Physics. In 1936 he returned to a lectureship in Cambridge, in charge of his own research group. A year later Rutherford died, and subsequently Feather found himself with more responsibility for the nuclear work in the Cavendish Laboratory. During the war years he carried a very heavy administrative load, both in the teaching programme and in the war-time work on nuclear fission.
In 1945 Feather was elected to the Fellowship of the Royal Society, and appointed to the Chair of Natural Philosophy in Edinburgh. He occupied this chair, as Head of Department, for 30 years. His first task in Edinburgh was to build up a department in which the techniques which had transformed nuclear experimentation during the war years could be developed and exploited. He was joined by a number of talented young men, and work was soon under way in the $\beta$ and $\gamma$-ray spectrometry of (mainly) naturally radioactive species, and in radiation chemistry and fast-neutron physics. Feather was not a man to stifle or constrain those of his staff who wanted to work in other fields, and projects on cosmic rays, meteorology, fluid dynamics and metal physics got under way too. The undergraduate curriculum was drastically overhauled, and by his own example Feather transmitted his view of the interdependence of undergraduate teaching, postgraduate training, and research.

With his Department running smoothly, Feather for a time concentrated his energies on writing and produced a series of texts aimed at undergraduates. Although his rather mannered style was not altogether congenial to the undergraduates of the $1950 \mathrm{~s}$ and $1960 \mathrm{~s}$, the combination in these books of care for language, extensive knowledge, and a scholarly and disciplined approach, was an affirmation of values which the author felt impelled to exhibit to his students.

In the 1960s Feather's attention turned again to the fission process, and a series of papers followed which dealt with the process of ternary fission, and especially the $\alpha$-particles emitted in fission. His lifelong interest in the various aspects of $\alpha$-emission continued into his retirement. His penultimate paper, published in 1978 , discussed the two solutions that have been proposed to the problem of the polonium haloes in mica. Something of the essence of the man flashes out in a characteristic sentence: 'Because these two suggestions appear to exhaust the logical possibilities of explanation, it is tempting to admit that one of them must be basically correct, but whoever would make this admission must be fortified by credulity of a high order.'

Feather's keen and incisive mind and his remarkable detachment made him a distinguished academic administrator. 
His services to such bodies as the Scottish Universities Entrance Board, the Home Defence Scientific Organization, and the Royal Society of Edinburgh (which he served for many years, as Councillor, as General Secretary, and then as President) were generously given and widely appreciated. The University of Edinburgh acknowledged his notable services to the University community by the award of the Honorary Degree of Doctor of Laws, just a few weeks after he retired.

R. M. Sillitto

\section{Herbert Dingle}

THE well-known spectroscopist, astrophysicist, philosopher of science and critic of relativity, Herbert Dingle, died in Hull on 4 September 1978, not long after his 88 th birthday.

Although of Cornish descent, Dingle was born in London, close to his beloved Surrey county cricket ground, the Oval, on 2 August, 1890. He spent most of his boyhood and youth in Plymouth, where his mother had returned on the death of her husband. After leaving school at the age of fourteen, Dingle worked for over ten years as a clerk by day and studied, as best he could, by night. In 1915 he won a Royal Scholarship for Physics at Imperial College. He graduated in 1918, having already been appointed to the staff of his department. The same year he married Alice Westacott. She predeceased him by over thirty years. He remained devoted to her memory. They had one son who became an industrial chemist, but he too died before his father.

More than three-quarters of Dingle's academic career was spent at Imperia) College, where he was eventually promoted to a chair in natural philosophy in 1937. Originally, he specialised in spectroscopy under Alfred Fowler, the successor of Norman Lockyer. On Fowler's retirement in 1935, he became head of the spectroscopy section. Under Fowler, Imperial College had been in the forefront of physics, in the great days of line spectroscopy follow. ing the introduction of the Bohr atom. It was no fault of Dingle's that his time as head of the spectroscopy section coincided with a world-wide lull in the subject, prior to its revival, under the impact of nuclear physics, in the nineteen-fifties. Nevertheless, Dingle did useful work in spectrochemical analysis and pioneer research on the spectra of fluorine II and III. He wrote much on the laboratory and astronomical applications of spectroscopy.

His book Modern Astrophysics, published in 1924, was one of the first on that subject. He was also part author of The Splendour of the Heavens, published in 1923, and The
Life and Work of Sir Norman Lockyer, published in 1929.

From the early nineteen-twenties Dingle was actively concerned with the philosophical as well as with the practical aspects of physics. He developed a highly professional interest in the philosophy of science and as a writer in that field he became very well known, particularly in the United States, which he visited for two lengthy periods in the thirties, the second time as Lowell Lecturer at Harvard. During the prolonged absence of Sir George Thomson from Imperial College during World War II Dingle was effectively in charge of the physics department.

Dingle's philosophy of science, as expounded in his books Science and Human Experience (1931) and Through Science to Philosophy (1937), the latter based on his Lowell Lectures, was in the new unfashionable tradition of British empiricism. He believed that the essential basis of science was the rational correlation of elementary experiences which can be made objective. This led him to adopt a philosophy which had much in common with that of Ernst Mach.

In 1946 Dingle was appointed Professor and Head of the Department of History and Philosophy of Science at University College, London, a post that he held until his retirement in 1955. Although no longer active in spectroscopy and astrophysics, he was elected President of the Royal Astronomical Society from 1951 to 1953. $\mathrm{He}$ was also President of Commission 41 (History of Astronomy) of the International Astronomical Union for some years and was a Vice-President of the International Union for the History of Science from 1953 to 1956 . He founded in 1948 the Philosophy of Science Group of the British Suciety fur the History of Science (which later became the British Society for the Philosophy of Science). Two years later, with the support of the late Dr H. P. Morrison of the publishing firm Nelson, he founded The British Journal for the Philosophy of Science. From 1955 to 1957 he was President of the British Society for the History of Science.

In the latter year he began his famous campaign against the special theory of relativity which dominated the last twenty years of his life. He had originally been sympathetic to the theory, particularly because of the ostensibly 'operational' philosophy that had guided Einstein in its creation, and in 1940 he published a Methuen monograph on it. His doubts originated when, while reading Sir George Thomson's The Foreseeable Future, he came across a passage relating to the 'clock paradox'. As a result, he engaged in a controversy in the correspondence columns of Nature with Professor W. H. McCrea, FRS, which led to a tremendous resurgence of interest in the 'paradox' and a spate of publications on it.

Later Dingle attacked the entire concept of relativistic time. His basic objection was that, according to the theory, two similar clocks, $A$ and $B$, in uniform relative motion $V$ work at different rates, but since the relation of each to the other is symmetrical it follows that, if $A$ works faster then $B$, $B$ must work faster than $A$. He argued that this was a contradiction and so the theory must be false. The point at issue was a subtle one and concerned the way in which Dingle used a particular concept which he called 'rate of clock'. He exemplified this by taking $A$ and $B$ to be together at epoch zero according to each and introducing two other clocks $H$ and $N$ at rest relative to $A$ and $B$, respectively, but not spatially coincident with them. He

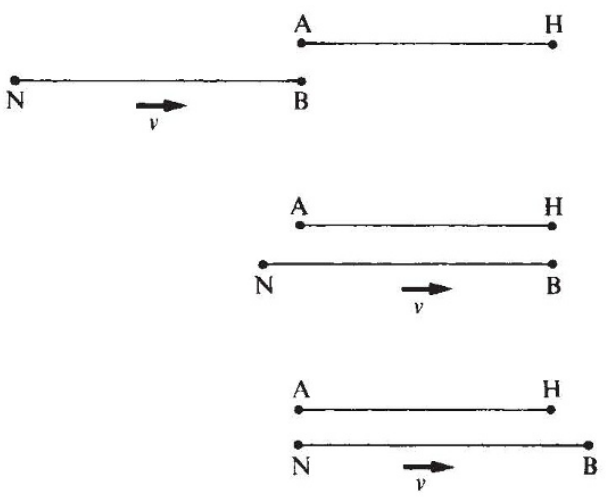

compared the times $t_{1}, t_{1}^{\prime}$ assigned to the epoch of $B$ 's momentary coincidence with $I H$ by the observers using the clocks $A, B$ respectively, and the corresponding times $t_{2}, t_{2}^{\prime}$ assigned to the epoch of $A$ 's momentary coincidence with $N$. He then argued that, since special relativity led to the formulae, $t_{1}=\beta t^{\prime}{ }_{1}, t_{2}^{\prime}=\beta t_{2}$, where $\beta$ is the reciprocal of $V\left(1-V^{2} / c^{2}\right)$, a contradiction results. This is because in the former case the ratio of the 'rates' of clocks $A$ and $B$ is given by $t_{1} / t^{\prime}{ }_{1}$ and in the latter case by $t_{2} / t^{\prime}{ }_{2}$, and hence this ratio has two incompatible values.

The difficulty can be resolved by rejecting Dingle's assumption that ratios such as $t_{1} / t^{\prime}{ }_{1}$ determine invariant relative 'rates' of clocks $A$ and $B$. His implicit requirement that the epochs assigned to any event by $A$ and $B$, respectively, should always be in the same ratio would imply that by a new choice of time unit for one of these clocks it could be arranged that the times assigned to any given event by $A$ and $B$ would be the same. Dingle's requirement is therefore equivalent to adopting the Newtonian concept of 